\title{
Stabilisation of Martensite During Training of Cu-Al-Ni Single Crystals
}

C. Qingfu(1), I. Hurtado, R. Stalmans and J. Van Humbeeck

Dep. MTM, de Croylaan 2, B-3001 Heverlee, Belgium

\begin{abstract}
Cu}-\mathrm{Al}-\mathrm{Ni}$ single crystals with composition $82.6 \mathrm{Cu}-13.4 \mathrm{Al}-4 \mathrm{Ni}$ (wt\%) were heat treated at $800^{\circ} \mathrm{C}$ for $30 \mathrm{~min}$ and subsequently water quenched to room temperature. The samples with $3 \mathrm{~mm}$ diameter and length between 100 and $200 \mathrm{~mm}$ had a longitudinal orientation close to the [001] direction of the $\beta$-phase at high temperature. The martensite start temperature after the initial heat treatment was $\mathrm{M}_{\mathrm{s}}=93^{\circ} \mathrm{C}$. Training was performed by loading the sample above $\mathrm{A}_{\mathrm{f}}$, followed by cooling under constant load. After removal of the load the sample was heated to recover its original shape. Repeating this cycle several times introduces the two-way memory effect. Several strains involved in the process were measured. It was found that a large residual deformation (RD) persisted after cycling between the training temperatures. Most of this residual deformation was recovered by overheating the sample. The non recoverable residual strain was observed to increase with increasing load. From the overheating experiments and differential scanning calorimetry measurements, it becomes evident that the total residual deformation is due to two contributions: the stabilisation of martensite and a plastic deformation.
\end{abstract}

\section{INTRODUCTION}

As a high temperature shape memory alloy, much attention has been paid to Cu-Al-Ni: effects of heat treatment on the transformation, mechanical behaviour [1], precipitation [2] and thermal stability [3, 4]. Although there have been several studies on the two way memory effect $[5,6]$, there is still a lack of data, especially with respect to the development of the two way memory effect (TWME) during training, and the stability of the shape memory effect.

The present paper describes the stabilisation of martensite during shape memory training in $\mathrm{Cu}-\mathrm{Al}-\mathrm{Ni}$ single crystals. The work mainly concentrates on the residual deformation (RD) and overheated trained samples. The thermomechanical cycling of the alloy, the relationships of stress assisted transformation effect (SATE) and the two way memory effect (TWME) are also presented.

\section{EXPERIMENTAL}

Thermomechanical cycling was performed with the testing apparatus described in the reference [7], for such apparatus can supply uniform training routines to obtain training results independently of sample geometry and thermal dilatation of the apparatus parts. An uniaxial tensile stress is applied on the sample. The load precision is $1 \mathrm{~N}$. The change of the sample length is measured with a Linear Variable Differential Transformer (LVDT) which is connected with the sample by quarts rods, the precision is

(1) On leave from Liaoning Institute of Technology, Jinzhou, China 
$2 \mu \mathrm{m}$. The temperature precision is controlled at $0.1^{\circ} \mathrm{C}$. The data (time, temperature, stress and strain) are sampled, logged and processed by a PC-AT computer.

The alloy studied has a nominal composition of $82.6 \mathrm{Cu}-13.4 \mathrm{Al}-4.0 \mathrm{Ni}$ (wt\%). Single crystals have been produced by the Stepanov method and purchased at ALKOR Cíe. in St. Petersburg. Samples for thermomechanical cycling are $3 \mathrm{~mm}$ in diameter and $100-200 \mathrm{~mm}$ long. The long side of the sample is close to the [001] direction of the $\beta$-phase at high temperature. Previously to the training process all the samples were heat treated $800^{\circ} \mathrm{C}$ for $30 \mathrm{~min}$ and subsequently water quenched to room temperature (W.Q.). After this homogenisation process, the transformation temperatures measured by DSC are: $M_{s}=93^{\circ} \mathrm{C}, M_{p}=84^{\circ} \mathrm{C}, M_{f}=59^{\circ} \mathrm{C}, A_{s}=76^{\circ} \mathrm{C}, A_{p}=97^{\circ} \mathrm{C}$ and $A_{f}=108^{\circ} \mathrm{C}$, where the sub indexes $s, p$ and $f$ indicate, respectively, the start, peak and end of the recorded DSC curve during the transformation.

Figure 1 shows the general thermomechanical cycling procedure used [7]. The subscripts in the text correspond with the positions indicated in this figure. Training was performed by loading the sample above $A_{f}(A-B)$, followed by cooling under constant load (B-C). After removal of the load (C-D), the sample was heated to recover its original shape. For the general training cycle, $T_{A}=136^{\circ} \mathrm{C}, T_{C}=48^{\circ} \mathrm{C}$, and the heating/cooling rate was $6^{\circ} \mathrm{C}$ per min. Each training cycle (A-B-C-D-E) was followed by a thermal cycle to investigate the two way memory behaviour (E-F-G).

In this paper several strain definitions, during and after the training process, are used following those in [7]. They are summarised in figure 2. Note that the one way memory effect is directly related to the SATE, the term TWME is the spontaneous shape change from a "hot" austenite shape to a "cold" martensite shape; and the term $\mathrm{RD}$ is the residual deformation of the austenite shape.

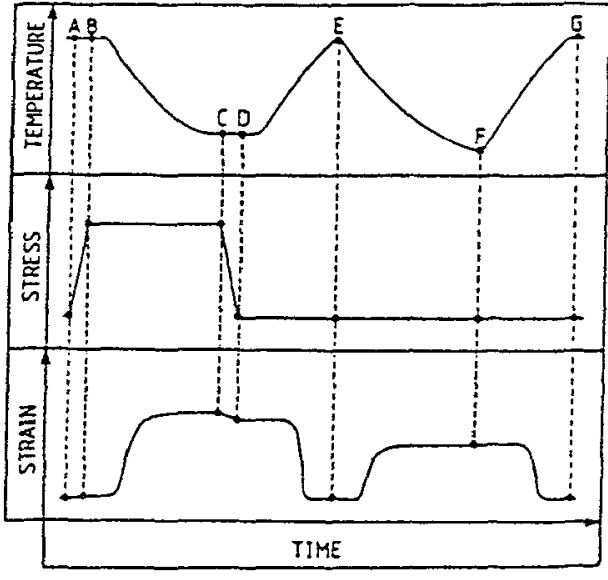

Figure 1. Thermomechanical cycling procedure used during the training [7]

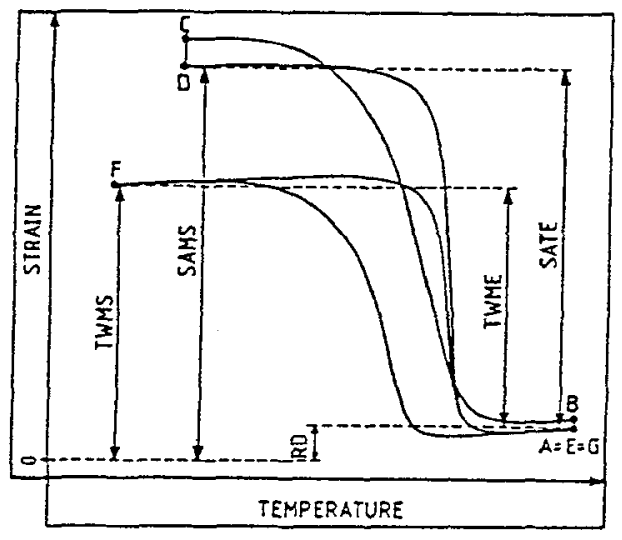

Figure 2. The $n$th training and subsequent thermal cycle with marking of the most important terms used in the text; TWME: two way memory effect; SATE: stress assisted transformation effect; RD: residual deformation of the austenite shape; TWMS: two way martensite strain; SAMS: stress assisted martensite strain

\section{RESULTS AND DISCUSSION}

\subsection{Changes in the values of the different types of strain during training}

In order to investigate the development of the strains (such as residual deformation RD, strain at loading, SAMS, SATE and TWMS), samples were systematically trained with stress $=10.0,17.8,24.0,36.1,48.1$ 
and 72.2 MPa respectively. Figure 3 is an example of the values obtained. It can be seen that the four strains mainly change within the first 7 training cycles. This implies that the first 7 training cycling may play an important role during training. When training stress is controlled between $24.0-72.2 \mathrm{MPa}$, the SATE decreases with increasing training number and finally all are stable at about $2.0 \%$.

Figure 4 shows TWMS vs. training number under different stresses. It can be seen that for each training stress, each TWMS saturates at a certain training number. For example, at $17.8 \mathrm{MPa}$, the TWMS saturates at $0.23 \%$ after the second cycle; at $36.1 \mathrm{MPa}$, at $2.3 \%$ after the 4 th cycle; at $72.2 \mathrm{MPa}$, at $3.4 \%$ at the 9th cycle. Thus, the TWMS saturation level increases with increasing training stress while also the corresponding cycling number increases. This evolution of the TWMS value is a direct consequence of the evolution of the residual strain /fig $2 /$, which will be described in the next section.

It has also been observed that the TWME increases linearly as a function of the training stress, figure 5.

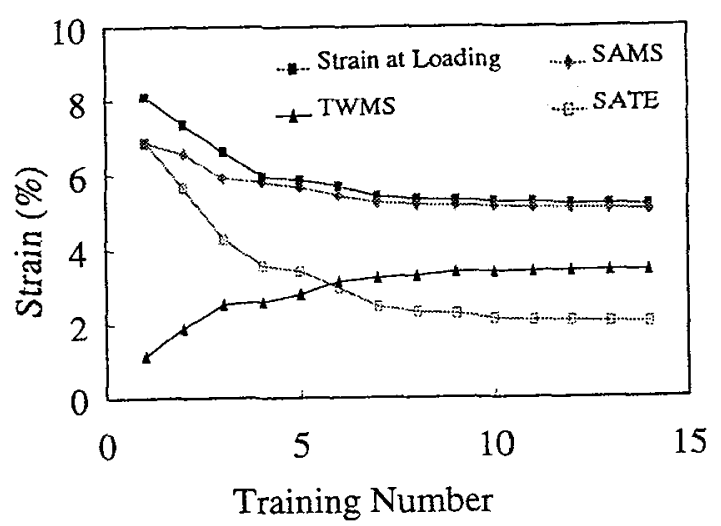

Figure 3. Strains vs, training number for a training stress of $72.2 \mathrm{MPa}$

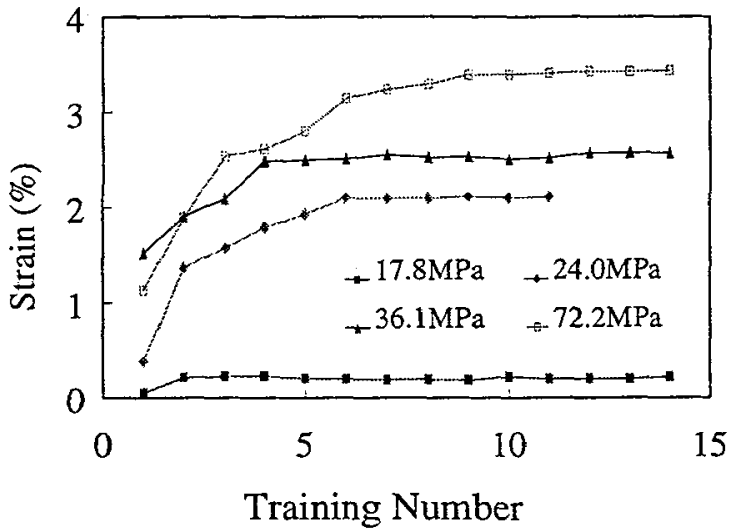

Figure 4. TWMS vs, training number for different training stresses

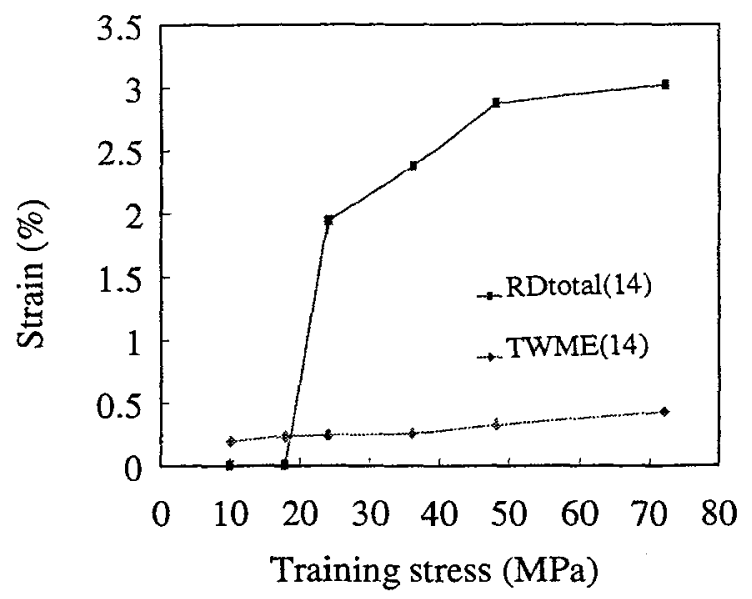

Figure 5. Residual deformation (RD) and TWME vs, training stress

\subsection{Stabilisation and Residual Deformation}

Attention should be paid to the change of the residual deformation in figure 5. A large residual 
deformation (RD) persists after 14 training cycles when the training stress is above $24.0 \mathrm{MPa}$, and the RD increases with training stress.

After the samples were trained 14 cycles with different stresses between 48 and $136^{\circ} \mathrm{C}$, they were overheated up to $178^{\circ} \mathrm{C}$ and then cooled to $45^{\circ} \mathrm{C}$, figure. $6(a)$. The residual deformation was recovered nearly completely by overheating. However, the TWME was not improved even after a second overheating cycle.

By comparing the shape change of the 14 th training cycle $/ f i g .6(b) /$ with its overheating curve $/ f i g .6(a) /$, it can be seen that the broadness of the two way memory hysteresis curve becomes smaller after overheating $\left(86-105^{\circ} \mathrm{C}\right)$, compared with that of the 14 th training cycle before overheating $\left(78-134^{\circ} \mathrm{C}\right)$.

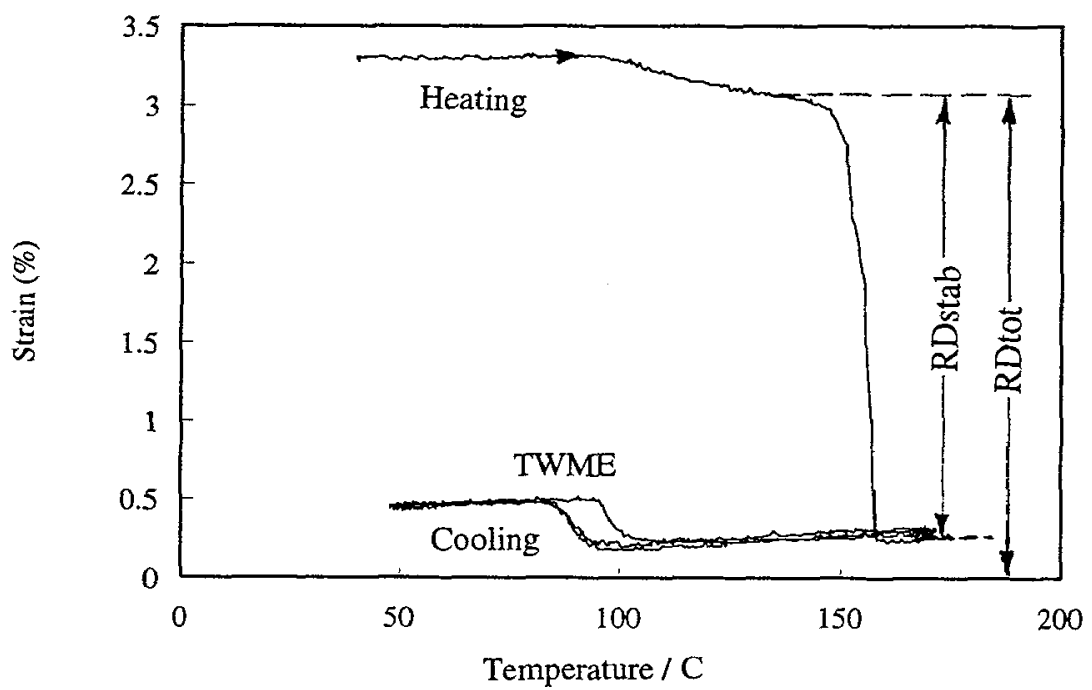

Figure 6 (a). Evolution of the residual deformation and TWME during an overheating experiment for a sample trained 14 cycles under a stress of $72.2 \mathrm{MPa}$

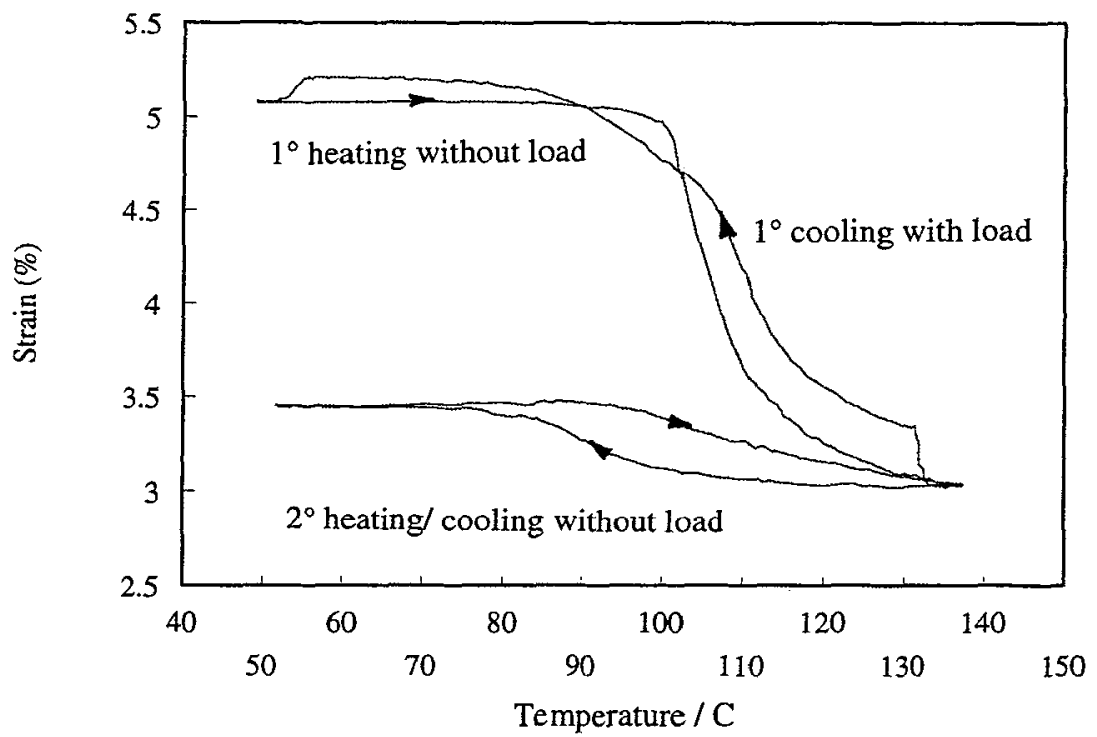

Figure $6(\mathrm{~b})$. Shape change during the 14 th training sample, training stress $=72.2 \mathrm{MPa}$ 
The effect of overheating has also been investigated by DSC (DuPont 2100) for two specimen cut out from a sample trained for 14 cycles with a stress of $72.2 \mathrm{MPa}$. An example is shown in figure 7. During the first heating cycle, from $50^{\circ}$ to $178^{\circ} \mathrm{C}$ and at a heating rate of $6^{\circ} \mathrm{C} / \mathrm{min}$, there is only one sharp exothermal peak at $166^{\circ} \mathrm{C}$ (without normal reverse transformation peak). However, during the second cycle (represented as $2^{\circ}$ in figure 7), it is shown that the sharp exothermal peak has disappeared, and there is only one exothermal peak which lies between $84^{\circ}$ and $98.5^{\circ} \mathrm{C}$. The obtained exothermal peak position corresponds quite well with that of the original one $\left(800^{\circ} \mathrm{C} 30 \mathrm{~min}\right.$, W.Q., DSC 2 nd heating). The heat exchange measured for both reverse transformations is nearly equal, about $10 \mathrm{~J} / \mathrm{g}$.

The results obtained from both thermomechanical overheating experiments and DSC measurements indicate that the recovery of residual deformation during overheating results from the recovery of the retransformation of stabilised martensite. This kind of stabilised martensite is formed during thermomechanical cycling. Thus, the RD after 14 cycles consists of two parts:

$$
\mathrm{RD}_{\text {total }}=\mathrm{RD}_{\text {stab }}+\mathrm{RD}_{\text {plas }}
$$

where $\mathrm{RD}_{\text {stab }}$ is caused by the stabilisation of martensite, and $\mathrm{RD}_{\text {plas }}$ is caused by plastic deformation during the thermomechanical cycling with large stress. $R D_{\text {plas }}$ is a non-recoverable residual deformation. Figure 8 shows the relationship between $\mathrm{RD}_{\text {total }}, \mathrm{RD}_{\text {stab }}$ and $\mathrm{RD}_{\text {plas }}$. The $\mathrm{RD}_{\text {stab }}$ is nearly constant, $2.8 \%$, for training cycles other than the initial ones, when the training stress is larger than $50 \mathrm{MPa}$. Such a $\mathrm{RD}_{\text {stab }}$ can be considered as the saturating stabilised martensite strain for the studied single crystal. A training stress larger than $50 \mathrm{MPa}$ can induce a large amount of plastic deformation during thermomechanical cycling and it increases with training stress.

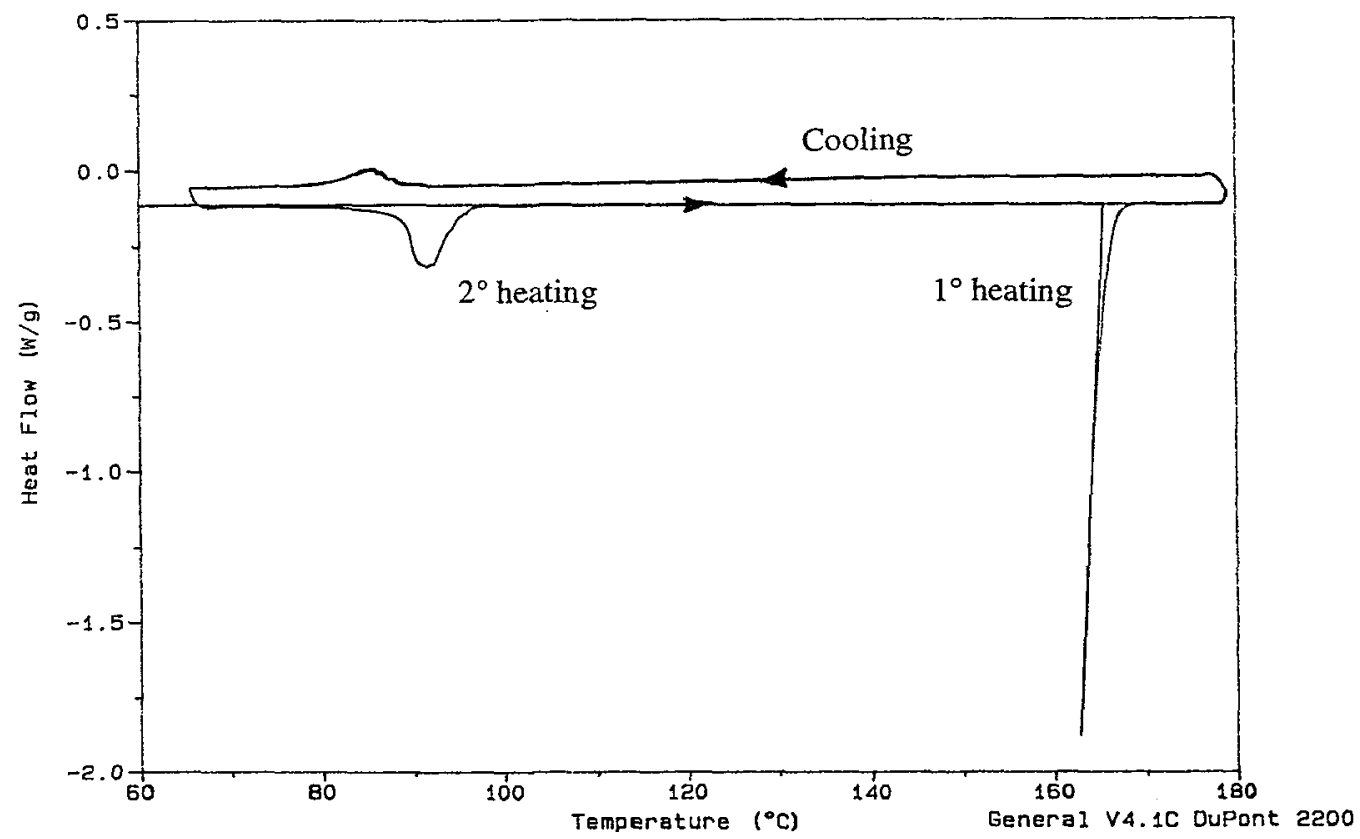

Figure 7. DSC overheating measurement for a sample previously trained 14 cycles under a stress of $72.2 \mathrm{MPa}$.

In figure 9 is presented the evolution of the total residual deformation as a function of the stress and for different training cycles. It is interesting to notice the decrease in the total plastic deformation during the 
first training cycle for stress values above $50 \mathrm{MPa}$. This decrease is related with a smaller contribution of

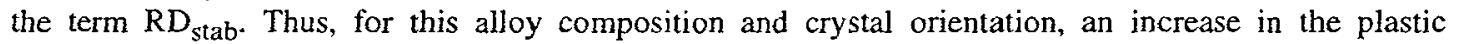
deformation during training has the effect of decreasing the amount of residual deformation due to the stabilisation of the martensite in the initial cycle. This effect could be due to either an effective decrease in the amount of stabilised martensite or to a directional strain effect in the measured direction.

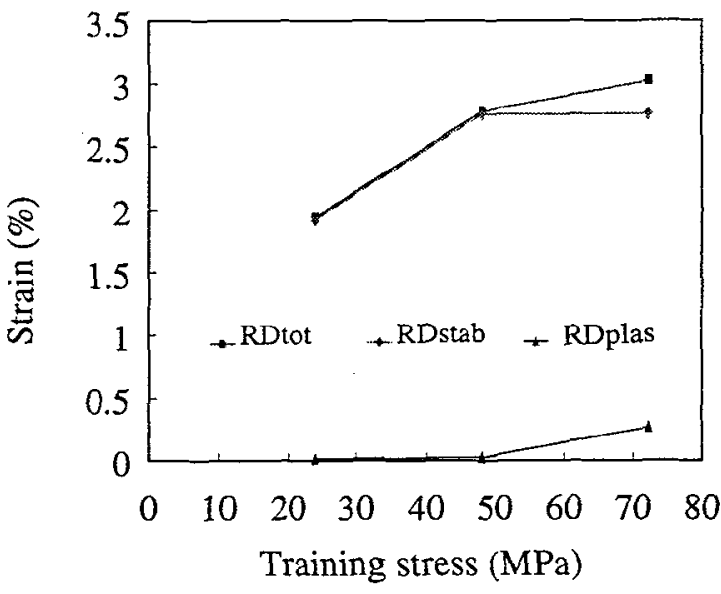

Figure 8. Relationship between $\mathrm{RD}_{\text {total }}, \mathrm{RD}_{\text {stab }}$ and $\mathrm{RD}_{\text {vlas }}$ for the 14th training cycle.

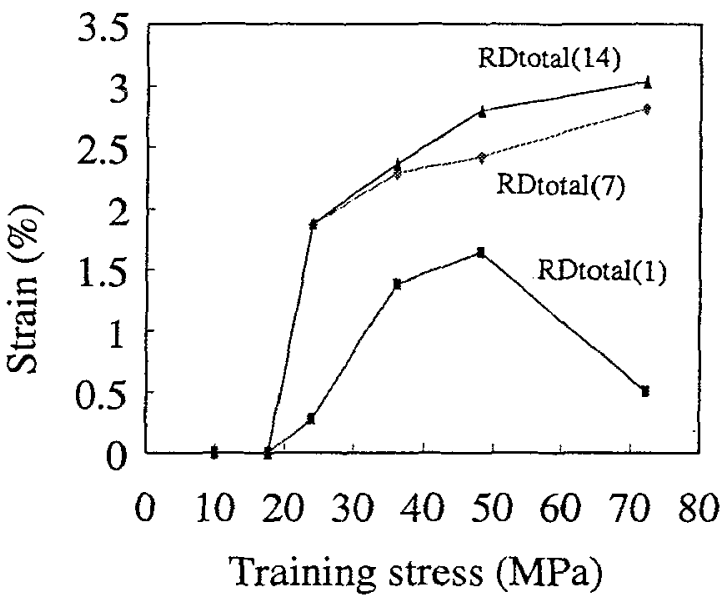

Figure 9. Evolution of the total residual deformation as a function of the stress and for different training cycles

\section{CONCLUSIONS}

* The measured residual deformation, $\mathrm{RD}_{\text {total }}$, is the result of two contributions: the deformation due to the non retransforming martensite, $\mathrm{RD}_{\mathrm{stab}}$, and the plastic deformation produced during the training, $\mathrm{RD}_{\text {plas. }}$

* The term $\mathrm{RD}_{\text {stab }}$ is due to the martensite stabilised during the training and can be completely recovered by an overheating of the sample. This is the main contribution to the total Residual Deformation for applied stresses below $50 \mathrm{MPa}$. Above this value the plastic deformation becomes important.

* The total residual deformation, up to the present maximum stress $(72.2 \mathrm{MPa}), \mathrm{RD}_{\text {total }}$, increases with the number of training cycles and the applied stress level, but for the initial training cycles. In this case the $\mathrm{RD}_{\text {total }}$ first increases until a maximum and then decreases for increasing values of the applied training stress. The decrease in $\mathrm{RD}_{\text {total }}$ is due to a decreases in the term $\mathrm{RD}_{\text {stab }}$, whereas the term $R D_{\text {plas }}$ continuously increases with increasing applied stress, especially above $50 \mathrm{MPa}$. So, during the first training cycles and for this specific single crystal composition and orientation, an increase in plastic deformation hinders the residual deformation due to the stabilisation of the martensite.

\section{REFERENCES}

1. H. Sakamoto and K.H. Shimizu, Mem. Inst. Sci. Ins. Res., Osaka Univ., 46 (1989) 99-110

2. Jogender Singh, Haydn Chen and C.M.Wayman, Scripta Met. 19 (1985) 231-234

3. K. Sugimoto et al, Engineering Aspects of SMA (1992) 89-95

4. Ming and $\mathrm{H}$. Wu ibid, $69-88$

5. P. Rodriguez, Doctoral Thesis, INSA Lyon (1989)

6. F.Trivero, M. Morin and G. Guénin, Proc. ICOMAT-92 (1992) 1307-1312

7. R.Stalmans, J.Van Humbeeck and L.Delaey, Acta Metall. Mater.40 (1993) 501-511 